\title{
O uso de materiais nanoestruturados nas infecções endodônticas: revisão de literatura
}

\author{
The use of nanostructured materials in endodontic infections: literature review \\ El uso de materiales nanoestructurados en infecciones endodónticas: revisión de la \\ literatura
}
Jéssica Priscila Moutinho Barbosa Silva ${ }^{1}$, Érica Cristina da Silva Rocha ${ }^{1}$, Edilaine Soares dos Santos ${ }^{1 *}$.

\section{RESUMO}

Objetivo: Apresentar uma revisão de literatura sobre o uso de materiais nanoestruturados no diagnóstico e tratamento de infecções endodônticas. Revisão bibliográfica: Os estudos mostraram que a incorporação da nanotecnologia na endodontia surge como uma alternativa que pode criar novos materiais e potencializar a ação antimicrobiana dos materiais já existentes no arsenal endodôntico, assim como auxilia no diagnóstico de dentes com infecções endodônticas. Ademais, age promovendo sinergismo na atividade antibacteriana, proporcionando remoção ainda mais eficaz dos microrganismos sobreviventes à instrumentação do preparo químico-mecânico, o que leva a proporcionar um ambiente hostil que dificultará o desenvolvimento bacteriano. Considerações finais: A nanotecnologia vem sendo explorada e desenvolvida nos últimos tempos e tem se mostrado uma alternativa bastante promissora na endodontia por permitir novas facetas aos materiais e seus campos de aplicação. Entretanto, por ser um assunto recentemente adotado na área, faz-se necessário que mais pesquisas sejam realizadas para tornar essa tecnologia uma opção cada vez mais presente na área da endodontia.

Palavras-chave: Endodontia, Nanotecnologia, Tratamento do Canal Radicular.

\begin{abstract}
Objective: To present a literature review on the use of nanostructured materials in the diagnosis and treatment of endodontic infections. Literature review: Studies have shown that the incorporation of nanotechnology in endodontics emerges as an alternative that can create new materials and enhance the antimicrobial action of existing materials in the endodontic arsenal, as well as assisting in the diagnosis of teeth with endodontic infections. It also acts by promoting synergism in antibacterial activity, providing even more effective removal of microorganisms surviving the instrumentation of the chemical-mechanical preparation, which leads to providing a hostile environment that will hinder bacterial development. Final Considerations: Nanotechnology has been explored and developed in recent times and has shown to be a very promising alternative in endodontics because it allows new facets to materials and their fields of application. However, as it is a recently adopted subject in the area, it is necessary that more research be done to make this technology an increasingly present option in the area of endodontics.
\end{abstract}

Key words: Endodontics, Nanotechnology, Root Canal Treatment.

\section{RESUMEN}

Objetivo: Presentar una revisión de la literatura sobre el uso de materiales nanoestructurados en el diagnóstico y tratamiento de infecciones endodóncicas. Revisión bibliográfica: Los estudios han demostrado que la incorporación de la nanotecnología en la endodoncia surge como una alternativa que puede crear

1 Centro Universitário CESMAC, Maceió-AL. *E-mail: j_priscila@hotmail.com 
nuevos materiales y mejorar la acción antimicrobiana de los materiales existentes en el arsenal endodóntico, además de ayudar en el diagnóstico de dientes con infecciones endodóncicas. También actúa promoviendo la sinergia en la actividad antibacteriana, proporcionando una eliminación aún más efectiva de microorganismos que sobreviven a la instrumentación de la preparación químico-mecánica, lo que conduce a proporcionar un ambiente hostil que dificultará el desarrollo bacteriano. Consideraciones finales: la nanotecnología ha sido explorada y desarrollada en los últimos tiempos y ha demostrado ser una alternativa muy prometedora en endodoncia porque permite nuevas facetas a los materiales y sus campos de aplicación. Sin embargo, como es un tema recientemente adoptado en el área, es necesario que se realicen más investigaciones para hacer de esta tecnología una opción cada vez más presente en el área de la endodoncia.

Palabras clave: Endodoncia, Nanotecnología, Tratamiento del Canal Radicular.

\section{INTRODUÇÃO}

Nos últimos anos, podemos dizer que houve uma verdadeira revolução em relação ao tratamento endodôntico com a introdução de novas tecnologias e mudanças nos conceitos biológicos, com vistas a simplificar o trabalho profissional e assim oferecer um melhor tratamento ao paciente (LOPES HP, SIQUEIRA JF, 2015). No entanto, mesmo com todo esse avanço técnico-científico ainda somos desafiados a pesquisar um arsenal endodôntico que alcance a tão sonhada sanificação do sistema de canais radiculares. Nesse cenário, a nanociência e nanotecnologia surge como proposta inovadora com potencial para criar novos materiais e potencializar os já existentes, para facilitar o tratamento das patologias endodônticas (VIMBELA GV, et al., 2017).

As primeiras discussões sobre a nanotecnologia tiveram início no final da década de 50 onde o físico americano Richard Feynman, através de sua palestra intitulada "Há muito espaço na parte inferior" entregue na Caltech em 1959 foi apontado como a inspiração para o campo da nanotecnologia (ABIODUN-SOLANKE IMF, et al., 2014). O foco do seu discurso era sobre o campo da miniaturização e como ele acreditava que o homem criaria dispositivos cada vez menores e poderosos. A ideia de Feynman permaneceu praticamente não discutida até meados da década de 1980, quando o engenheiro do Massachusetts Institute of Technology (MIT), Kim Eric Drexler, publicou "Engines of Creation", um livro para popularizar o potencial da nanotecnologia molecular em 1986 e introduziu o termo nanotecnologia (RAI M, 2013).

O termo nano é derivado da palavra vavoç, palavra grega para anão, combinada com o substantivo para tamanho, metro. É considerado um nanomaterial aquele que, após sua síntese, apresenta partículas que atinjam dimensões entre 1 e 100 nanômetros $(\mathrm{nm})$ (SCHLEYER TL, 2000). Para se ter uma ideia do tamanho de um nanômetro, vale relembrar que a célula sanguínea só é visível ao microscópio óptico e esta possui em média $7 \mu \mathrm{m}$ de diâmetro que é equivalente a $7.000 \mathrm{~nm}$, ou seja, uma célula sanguínea pode chegar a ser de 70 a 7000 vezes maior que uma nanopartícula (KISHEN A, et al., 2016).

Devido às dúvidas criadas entre os termos nanociência e nanotecnologia, foi necessário diferenciá-los, sendo assim, Kishen A, et al. (2016) afirma que a nanociência dedica-se ao estudo e ao desenvolvimento de novos métodos de síntese e caracterização de materiais de escala nanométrica, com o objetivo de controlar o tamanho e as propriedades apresentadas e compreender o comportamento dos materiais; É de conhecimento científico que a nanotecnologia apresenta como característica a habilidade de produzir novos nanomateriais a partir de recursos de escalas atômicas que direciona cada átomo e cada molécula para 0 local almejado (SBRESTHA A, KISHEN A, 2016).

Nessa perspectiva, é possível obter os benefícios desse novo ramo da ciência na odontologia. As estruturas nanoméricas já estão sendo aplicadas na odontologia principalmente no que diz respeito à estética. Já se utiliza a nanoescala para o aprimoramento de instrumento endodônticos (limas), obtenção de novas substâncias e na dinâmica dos materiais utilizados no tratamento endodôntico, seja melhorando as suas propriedades ou concedendo novas funções aos compostos antimicrobianos (ALAPATI SB, et al., 2006).

Essa nanotecnologia tem sido amplamente aceita no mundo científico dos endodontistas, em razão de suas propriedades químicas, mecânicas, magnéticas, elétricas e óticas únicas. Podendo proporcionar 
melhorias na eficácia antimicrobiana, integridade mecânica da matriz de dentina previamente doente e regeneração tecidual (DEL POZO JL, PATEL R, 2007).

Acredita-se que os nanometais promovem liberação de íons metálicos tóxicos a partir da superfície das nanoestruturas, quando há a dissolução dos metais ou pelo estresse oxidativo devido à geração de espécies reativas de oxigênio (LINSEBIGLER AL, et al., 1995). Os últimos agem atacando os fosfolipídios da membrana bacteriana e causam alterações no DNA (HIRAKAWA K, et al., 2004).

Há indicações de que as bactérias sejam menos propensas ao desenvolvimento de resistência às nanoestruturas metálicas do que contra aos antibióticos, porque os metais possivelmente são capazes de atuar em vários pontos dos microrganismos, e muitas mutações seriam necessárias para que estes adquirissem resistência (PAL S, et al., 2007). Dentre as nanoestruturas utilizadas com ação antimicrobiana encontra-se a prata (JAVIDI M, et al., 2013), a quitosana (ZANGH FH, et al., 2016), e o titânio (VIMBELA GV, et al., 2017). Nesse contexto, o tratamento dos canais radiculares está sendo repaginado com o emprego da nanotecnologia como um fator importante na ação de desinfecção do canal e potencialização dos materiais utilizados no tratamento endodôntico. Além disso, os estudos científicos apontam para uma maior efetividade dos materiais quando estes são utilizados com nanoestruturas. Dessa forma, o presente artigo tem o objetivo de apresentar uma revisão de literatura sobre o uso de materiais nanoestruturados no tratamento de infecções endodônticas.

\section{REVISÃO BIBLIOGRÁFICA}

\section{Nanoestruturas e sua atividade antibacteriana}

Vários são os estudos que demonstram que os biofilmes bacterianos são considerados a principal causa de infecção do canal radicular (GOMES BP, et al., 2004). E por isso, os antimicrobianos químicos são usados topicamente dentro dos canais radiculares em combinação com instrumentação mecânica para alcançar uma redução microbiana efetiva antes de preencher o canal radicular com um material de enchimento inerte (DEL POZO JL, PATEL R, 2007; KISHEN A, 2012). Contudo, pesquisas evidenciam que apesar dos avanços nas estratégias de tratamento, a taxa de falha não diminuiu abaixo de $18 \%-26 \%$ nas últimas 4 a 5 décadas (DEL POZO JL, PATEL, 2007). Isso pode ser atribuído a vários fatores como a incapacidade ou limitações das tecnologias atuais para lidar com o processo da doença como um todo, as negligências técnicas ocasionadas na aplicação da prática clínica (KISHEN A, 2012). Assim, o manejo conservador de infecções envolvendo antibióticos tópicos ou sistêmicos se mostrou ineficaz, devido à vários fatores desafiantes, tais como bactérias resistentes a antibióticos (cepas mutantes), mecanismos de resistência a antibióticos (Enterococcus resistentes, trocas de materiais genéticos), estrutura e organização de microrganismos e por fim, uso indevido de antibióticos (D'COSTA VM, et al., 2011).

Dessa forma, devido às deficiências atuais no uso de antibiofilmes em tratamento do canal radicular, estão sendo desenvolvidas e testadas estratégias avançadas de desinfecção. Assim, as nanopartículas antibacterianas foram introduzidas em nível laboratorial com potencial significativo para eliminação de biofilmes endodônticos (KISHEN A, et al., 2008; SBRESTHA A, KISHEN A, 2016). Dentre as nanoestruturas utilizadas com ação antimicrobiana encontra-se a prata (JAVIDI M, et al., 2013), a quitosana (ZANGH FH, et al., 2016), e o titânio (VIMBELA GV, et al., 2017).

Pela primeira vez, Kishen A, et al. (2008), analisaram a eficácia de várias nanopartículas catiônicas para melhorar a desinfecção do canal radicular. Dentinas tratadas com nanopartículas resultaram em diminuição significativa na adesão de Enterococcus faecalis (E. faecalis). Kong WH, et al. (2007) utilizaram nanopartículas para o desenvolvimento de ferramentas de uso clínico a fim de funcionar como biomarcadores auxiliando no diagnóstico de lesões periapicais. Esses biomarcadores também tinham a função de reconhecimento de biofilme bacteriano.

Autores como Estrela C e Holland R (2003), afirmavam a eficácia da proteção pulpar através da dentina em associação ao hidróxido de cálcio. Na mesma linha, Komabayashi T, et al. (2009), perceberam que o hidróxido de cálcio poderia penetrar nos túbulos dentinários abertos. Entretanto, vários estudos mostram que 
devido à presença de smear layer, biofilme bacteriano e/ou pela formação de cálculo dentinário por nanobactérias, existe a dificuldade de promover a abertura dos túbulos dentinários, principalmente na região periapical, região crítica de formação de biofilme (MARCHESAN MA, et al., 2009; PAZ LCE, et al., 2007). Hernández-Sierra JF (2008), demonstrou o potencial de desinfecção dos materiais nanoméricos por meio da utilização de partículas de ouro, prata e óxido de zinco sobre o Streptococcus mutans (S. Mutans). Nesse sentindo, a ação da nanotecnologia por possuir uma maior superfície de contato, poderia agir potencializando o efeito das medicações, proporcionando uma melhoria entre a superfície de contato dentina/medicação, contribuindo para uma desinfecção mais eficaz (KISHEN A, et al., 2008).

Nessa mesma linha, Aguiar AS, et al. (2015) propuseram a utilização de pastas nano ou micropartículadas à base de hidróxido de cálcio, com e sem adição de clorexidina e verificaram um melhor efeito antimicrobiano para $E$. faecalis quando estas pastas estavam associadas à clorexidina e à nanoestrutura. Afirmando que as nanopartículas permitem maior e mais rápida penetrabilidade na dentina e nos túbulos dentinários, favorecendo o efeito químico e antimicrobiano no sistema de canais radiculares.

\section{Nanopartículas de prata}

As nanopartículas de prata foram amplamente utilizadas no campo biomédico, principalmente por causa de sua propriedade antibacteriana (VIMBELA GV, 2017). No caso de aplicação dentária, a prata e suas nanopartículas foram testadas para aplicação como material restaurador dentário, material de obturação retrógrada, implantes dentários e como solução inibitória de cárie (WU D, et al., 2014).

Seu mecanismo de ação está relacionado com a ação antibacteriana atuando de várias formas, desde a interação com os grupos fosfatos de proteínas e ácido desoxirribonucleico (DNA), promovendo alteração na cadeia de ligação de hidrogênio/cadeia respiratória, promovendo alteração no DNA por meio da interferência na síntese da parede celular/divisão celular. As nanopartículas de prata (Ag-NPs) são conhecidas por desestabilizar ainda mais a membrana bacteriana e aumento da permeabilidade, levando a vazamento de componentes celulares (HIRAKAWA K, et al., 2004)

Hiraishi $\mathrm{N}$, et al. (2010) testaram o fluoreto de diamina de prata em biofilmes de $E$. faecalis in vitro e verificaram eliminação completa dos microrganismos após 60 minutos de interação; 3,8\% de fluoreto de diamina de prata também foi encontrado depositado na superfície da dentina com penetração de $40 \mathrm{~mm}$ em túbulos dentinários.

Wu D, et al. (2014) mostraram que nanopartículas de prata tiveram uma maior eficácia quando aplicadas como medicação intracanal em relação à aplicação como solução irrigante na eliminação de biofilme. Eles afirmaram que $0,02 \%$ de gel Ag-NP como medicamento durante 7 dias foi significativamente melhor em $E$. faecalis em comparação com grupos de hidróxido de cálcio e irrigação de seringas com maior concentração de solução de Ag-NP (0,1\%). Sugerindo que, quando usado como medicamento, há uma interação prolongada entre Ag-NPs carregados positivamente e bactérias/estruturas de biofilme carregadas negativamente, resultando nesta diferença. A suspensão de Ag-NP, quando combinada com hidróxido de cálcio, reduziu significativamente $E$. faecalis em dentina do canal radicular (JAVIDI M, et al., 2013).

Pal S, et al. (2007) avaliaram a relação entre diferentes formas de nanopartículas de prata e a sua ação sobre microrganismos, especialmente a Escherichia coli (E. coli). Para isso, colocaram diferentes formas de nanopartículas de prata (esféricas, alongadas e triangulares) em contato com as bactérias. Os autores observaram que, em geral, a presença das nanopartículas inibiu o crescimento bacteriano em mais de $90 \%$ e que para cada uma das formas estudadas, diferentes concentrações de nanopartículas foram necessárias para essa inibição. Os autores concluíram que, provavelmente diferentes formas têm diferentes áreas de superfície de contato e que, consequentemente, influenciam no contato efetivo com as bactérias.

\section{Nanoestruturas de quitosana}

A quitosana é um derivado desacetilado de quitina, sendo o segundo biopolímero natural mais abundante. As nanopartículas de quitosana podem ser sintetizadas ou montadas usando diferentes métodos, dependendo da aplicação final ou das características físicas necessárias nas nanopartículas (CAMPANAFILHO SP, et al., 2007). Essa nanoestrutura tem interesse significativo na biomedicina por possuir estrutura semelhante aos componentes da matriz extracelular, sendo usada para reforçar construções de colágeno. 
Além da versatilidade em se obter várias formas do material, como pó (micro e nanopartículas), cápsulas, filmes, andaimes, hidrogéis, grânulos e ligaduras. Nanopartículas de quitosana foram desenvolvidas principalmente para aplicações de administração de antibacterianos e medicamentos/genes (AGNIHOTRI SA, et al., 2004).

Além de excelentes propriedades antibacterianas, possuem também propriedades antivirais e antifúngicas (MUZZARELLI C, MUZZARELLI RA, 2002). No caso de bactérias, as gram-positivas apresentamse mais suscetíveis do que as gram-negativas. Seu mecanismo de ação proposto é a destruição dos microrganismos, a qual é mediada por contato que envolve a atração eletrostática de quitosana, que por sua vez é carregada positivamente com membranas celulares bacterianas carregadas negativamente. Isso pode levar à alteração da permeabilidade da parede celular, resultando eventualmente na ruptura de células, vazamento dos componentes proteináceos e de outros componentes intracelulares, levando a aglutinação das células e a inibição de crescimento (CHÁVEZ DE PAZ L, et al., 2011).

Sob a microscopia eletrônica de transmissão, foi observado que as células bacterianas pareciam estar completamente envolvidas na quitosana, formando uma camada impermeável (MUZZARELLI C, MUZZARELLI RA, 2002). Isso pode resultar na prevenção de transporte de solutos essenciais que levam à morte celular. Em caso de fungos, a quitosana teve a hipótese de entrar na célula e atingir o núcleo, se ligar ao DNA e inibir a síntese de RNA e proteínas, interagindo com as cargas negativas da superfície da membrana das bactérias, levando à aglutinação das células e à inibição do crescimento (CHÁVEZ DE PAZ LE, et al., 2011). As principais vantagens de se utilizar nanopartículas de quitosana são a sua simplicidade e baixo custo de preparação, não necessitando de calor e solventes orgânicos, são reprodutíveis, estáveis e aplicáveis a uma grande categoria de substâncias: moléculas pequenas, proteínas e polinucleotídeos (AGNIHOTRI SA, et al., 2004). Ademais, quando incorporadas aos cimentos endodônticos e às soluções irrigadoras adquirem um efeito antibacteriano bastante relevante, além de apresentar baixos níveis de toxicidade (TELLES ISF, et al., 2017).

\section{Nanoestruturas de dióxido de titânio}

O dióxido de titânio $\left(\mathrm{TiO}_{2}\right)$ apresenta-se como três polimorfos distintos, denominados de anatase, com estrutura alongada, volumosa e desta forma, menos densa, a brookita que apresenta estabilidade apenas em condições específicas de pressão, e o rutilo que possui maior dureza, densidade, índice de refração, é termodinamicamente mais estável em altas temperaturas e o mais utilizado por pesquisadores em vários ramos da indústria, inclusive no desenvolvimento dos materiais odontológicos (WONG MS, et al., 2006) . A ampla aplicação deste material se deve às suas propriedades elétricas (semicondutores elétricos), fotoquímicas (fotocatalisador), óticas (alto índice de refração) e estruturais únicas, além de ser atóxico e biocompatível, apresentar alta estabilidade sobre condições adversas de temperatura, umidade e pH (CHEN X, MAO SS, 2007). Nogueira RFP e Jardim WF (1998) comprovaram o poder do $\mathrm{TiO}_{2}$ na inativação de microrganismos tais como Lactobacillus acidophilus, Saccharomyces cerevisiae e Escherichia coli.

Contudo as propriedades do $\mathrm{TiO}_{2}$ tornam-se melhores quando apresenta-se na forma nanoparticulada, pois as nanopartículas são homogêneas e quimicamente estáveis, além de apresentar grande área superficial (MENG X, et al., 2013). A atividade antibacteriana do $\mathrm{TiO}_{2}$ foi estudada por meio da fotocatálise por Wong MS, et al. (2006) contra vários patógenos humanos. Foi demostrado que o $\mathrm{TiO}_{2}$ dopado com nitrogênio tem atividade bactericida luz-visível-induzida contra todos os patógenos estudados (Escherichia coli, Shigella flexneri, Listeria monocytogenes, Vibrio parahaemolyticus, Streptococcus pyogenes, Staphylococcus aureus, e Acinetobacter baumannii) superior $\mathrm{ao}^{\mathrm{TiO}_{2}}$ puro, o que sugere sua potencial aplicação como desinfetantes ambientais. Esses resultados são comparáveis a tradicional atividade antibacteriana do $\mathrm{TiO}_{2}$ por fotocatálise induzida pela luz ultravioleta e pode ser uma alternativa viável em ambientes públicos, como hospitais, para reduzir a transmissão de patógenos e, consequentemente, diminuir os riscos de infecções.

Kaegi $\mathrm{R}$, et al. (2008) estudaram a detecção de nanopartículas de $\mathrm{TiO}_{2}$ comumente utilizadas em vários ramos da indústria, no ambiente aquático, uma vez que quando utilizadas, essas nanopartículas são liberadas gradativamente no meio ambiente. Para isso, os autores retiraram amostras da área urbana, que foram submetidas à microscopia eletrônica de varreadura (MEV) e microscopia eletrônica de transmissão (MET) 
para identificar as nanopartículas (quanto ao tamanho), e posteriormente, a análise de raio X por energia dispersiva (EDX) para identificação de sua composição, diferenciando as naturais das sintéticas. Tanto a microscopia, quanto o EDX mostraram ser instrumentos utilizados para a detecção das nanopartículas de $\mathrm{TiO}_{2}$ no ambiente aquático, auxiliando na avaliação de seu risco ambiental.

No estudo in vitro realizado por Santos ES, et al. (2018), para investigar a atividade antibacteriana de diferentes concentrações de nanotubos de dióxido de titânio $\left(\mathrm{TiO}_{2}\right)(1 \%$ e $3 \%)$ associado ao Calen e ao Calen com Paramonoclorofenol canforado (PMCC) para E. coli e E. faecalis verificou-se que os grupos experimentais que continham $\mathrm{TiO}_{2}$ apresentaram um maior halo de inibição em $E$. coli quando comparados aos grupos que não tinham $\mathrm{TiO}_{2}$, concluindo que a incorporação de $3 \%$ de $\mathrm{TiO}_{2}$ às duas pastas à base de hidróxido de cálcio se apresenta como uma proposta bastante favorável na inibição do crescimento da bactéria $E$. coli. Entretanto, nenhuma ação antibacteriana foi observada para E. faecalis.

É interessante salientar outro estudo in vitro realizado por Santos ES, et al. (2019) para avaliar o impacto na dissociação de íons cálcio e hidroxila em diferentes intervalos de tempo (0 h, 24 h, 96 h,164 h, 264 h, 336 h) a partir da adição de diferentes concentrações de nanotubos de dióxido titânio $\left(\mathrm{TiO}_{2}\right)$ ( 1 e 3\%), associados ao hidróxido de cálcio puro e com o PMCC. Foi constatada uma diferença expressiva na liberação de íons cálcio e hidroxila nas duas concentrações utilizadas. Entretanto, a concentração de $3 \%$ de $\mathrm{TiO}_{2}$ no Calen e $1 \%$ de $\mathrm{TiO}_{2}$ no Calen/PMCC, contribuiu para uma maior liberação de íons cálcio e hidroxila, indicando uma maior intensificação na atividade antibacteriana das medicações testadas.

É importante ressaltar que apesar do uso de materiais nanoestruturados já estar fazendo parte do mundo da endodontia, a aplicação bem sucedida das nanopartículas, quando utilizadas como irrigantes ou medicações, dependerá do tipo e tamanho da nanopartícula, da eficácia e do método de administração utilizado para dispersar essas partículas nas complexidades anatômicas do sistema de canais radiculares, que em geral são regiões não instrumentadas (TELLES ISF, et al., 2017). Ademais, os riscos da utilização destas substâncias ainda são indefinidos (RAI M, 2013).

Sendo assim, é notório os aspectos positivos da utilização da nanotecnologia e seu emprego na endodontia, sendo que alguns desses benefícios já são explorados no dia a dia clínico e outros ainda serão aprimorados. Além disso, pesquisas atentando para seus efeitos colaterais devem ser realizadas.

\section{CONSIDERAÇÕES FINAIS}

A nanotecnologia vem sendo explorada e desenvolvida nos últimos tempos e tem se mostrado uma alternativa bastante promissora na endodontia por permitir novas facetas aos materiais e seus campos de aplicação. Vale ressaltar que uma aplicabilidade de sucesso dependerá diretamente da eficácia contra os agentes microbianos e seu mecanismo de ação no interior do canal radicular. Outro aspecto que merece um maior aprofundamento diz respeito à comunicação das nanopartículas e os impactos causados ao organismo do paciente e ao meio ambiente, considerando que ainda existem poucas pesquisas neste âmbito, além da possibilidade de tornar essa tecnologia uma opção cada vez mais presente na prática clínica odontológica.

\section{REFERÊNCIAS}

1. ABIODUN-SOLANKE IMF, et al. Nanotechnology and its application in dentistry. Annals of Medical and Health Sciences Research, Vol. 4, Sep-Oct 2014.

2. AGNIHOTRI SA, et al. Recent advances on chitosan-based micro- and nanoparticles in drug delivery. Journal of Controlled Release, v.100, n.1, p.5-28, 2004.

3. AGUIAR AS, et al. Antimicrobial activity and $\mathrm{pH}$ of calcium hydroxide and zinc oxide nanoparticles intracanal medication and association with chlorhexidine. J Contemp Dent Pract. 2015;16(8):624-629.

4. ALAPATI SB, et al. Vickers hardness investigation of work hardening in used NiTi rotary instruments. Journal of Endodontic, v. 32, n. 12, Dec. 2006.

5. CAMPANA-FILHO SP, et al. Propriedades e aplicações de quitosana. Processos Químicos, v.1, n.2, 2007.

6. CHÁVEZ DE PAZ LE, et al. Antimicrobial effect of chitosan nanoparticles on streptococcus mutans biofilms. Applied and Environmental Microbiology, v.77, n.11, p.3892-3895, 2011.

7. CHEN J, et al. A gold nanoparticles/sol-gel composite architecture for encapsulation of immunoconjugate for reagentless electrochemical immunoassay. Volume 27, Issue 10, April 2006, Pages 2313-2321. 
8. CHEN X, MAO SS. Titanium dioxide nanomaterials: synthesis, properties, modifications, and applications. Chem Rev. 2007;107(7):2891-2959.

9. D'COSTA VM, et al. Antibiotic resistance is ancient. Nature Reviews. 2011;477:457-461. Doi:10.1038/nature1038.

10. DEL POZO JL, PATEL R. The Challenge of treating biofilm-associated bacterial infections. Clin Pharmacol Ther. 2007;82(2):204-209.

11. ESTRELA C, HOLLAND R. Hidróxido de cálcio: estudo baseado em evidências científicas, Journal of Applied Oral Science, 2003.

12. GOMES BP, et al. Microbiological examination of infected dental root canals. Oral Microbiol Immunol. 2004;19(2):7176.

13. HERNÁNDEZ-SIERRA JF. The antimicrobial sensitivity of Streptococcus mutans to nanoparticles of silver, zinc oxide, and gold. Nanomedicine: Nanotechnology, Biology, and Medicin, v. 4, p. 237-240, 2008.

14. HIRAISHI N, et al. Antimicrobial efficacy of $3.8 \%$ silver diamine fluoride and its effect on root dentin. J Endod. 2010 Jun;36(6):1026-9. doi: 10.1016/j.joen.2010.02.029. Epub 2010 Apr 24.

15. HIRAKAWA K, et al. Photo-irradiated titanium dioxide catalyzes site specific DNA damage via generation of hydrogen peroxide. Free Radic Res. 2004;38(5):439-447.

16. JAVIDI M, et al. Efficacy of a combined nanoparticulate/calcium hydroxide root canal medication on elimination of Enterococcus faecalis. Aust Endod J. 2014 Aug;40(2):61-5. doi: 10.1111/aej.12028. Epub 2013 May 12.

17. KAEGI R, et al. Synthetic TiO2 nanoparticle emission from exterior facades into the aquatic environment. Environ Pollut. 2008;156(2):233-239.

18. KISHEN A, et al. Advances in endodontics: potential applications in clinical practice. J Conserv Dent. 2016;19(3):199206.

19. KISHEN A, et al. An investigation on the antibacterial and antibiofilm efficacy of cationic nanoparticulates for root canal disinfection. Journal Of Endodontics, v. 34, n. 12, dec. 2008.

20. KISHEN A. Advanced therapeutic options for endodontic biofilms. Endod Topics 2012;22(1):99-123.

21. KOMABAYASHI T, et al. Particle Size and Shape of Calcium Hydroxide. Journal of Endodontic, v. 35, n. 2, p. $284-$ 287, Feb 2009.

22. KONG WH, et al. Nanoparticulate carrier containing water-insoluble iodinated oil as a multifunctional contrast agent for computed tomography imaging. Biomaterials, v. 28 p. 5555-5561, 2007.

23. LINSEBIGLER AL, et al. Photocatalysis on $\mathrm{TiO}_{2}$ surfaces: principles, mechanisms, and selected results. Chem Rev. 1995;95(3):735-758.

24. LOPES HP, SIQUEIRA JF. Endodontia, Biologia e Técnica. 15eded. São Paulo: Elsevier; 2015.

25. MARCHESAN MA, et al. Morphometrical analysis of cleaning capacity using nickeltitanium rotary instrumentation associated with irrigating solutions in mesio distal flattened root canals. J Appl Oral Sci, v. 11, no 1, p 55-59, 2003.

26. MENG X, et al. Controllable atomic layer deposition of one-dimensional nanotubular $\mathrm{TiO}_{2}$. Appl Surf Scien. 2013;266(2013):132-140.

27. MUZZARELLI C, MUZZARELLI RA. Natural and artificial chitosan-inorganic composites. Journal of Inorganic Biochemistry, v.92, n.2, p.89-94, 2002.

28. NOGUEIRA RFP, JARDIM WF. A fotocatálise heterogênia e sua aplicação ambiental. Quím. 21(1):69-72, jul. 1998.

29. PAL S, et al. Does the antibacterial activity of silver nanoparticles depend on the shape of the nanoparticle? A study of the gram-negative bacterium Escherichia coli. Appl Environ Microbiol. 2007;73(6):1712-1720.

30. PAZ LCE, et al. Response to alkaline stress by root canal bacteria in biofilms. International Endodontic Journal, v. 40, p. 344-355, 2007.

31. RAI M. Nanobiotecnologia verde: biossíntese de nanopartículas metálicas e suas aplicações como nanoantimicrobianos. Ciênc. Cult, vol. 65, n. 3, São Paulo, 2013.

32. SANTOS ES, et al. Nanotecnologia incorporada à medicacão intracanal à base de hidróxido de cálcio influenciam na dissociação de íons cálcio e no pH? Braz Oral Res 2019;33(suppl 2).

33. SANTOS ES, et al. Nanotecnologia melhora as propriedades antimicrobianas de pasta endodôntica à base de hidróxido de cálcio? Braz Oral Res 2018;32(suppl 2).

34. SBRESTHA A, KISHEN A. Antibacterial nanoparticles endodontics: a narrative review. J Endod. 2016;42(10):14171426.

35. SCHLEYER TL. Nanodentistry: fact or fiction? Journal of American Dental Association, v.131, p.1567-1568; 2000.

36. TELLES ISF, et al. Nanopartículas e aplicações endodônticas: uma revisão de literatura. Rev. Bras. Odontol., Rio de Janeiro, v. 74, n. 2, p. 167-175, abr./jun. 2017.

37. VIMBELA GV, et al. Antibacterial properties and toxicity from metallic nanomaterials. Int J Nanomedicine. 2017;24(12):3941-3965. doi: 10.2147/IJN.S134526.

38. WONG MS, et al. Visible-lightinduced bactericidal activity of a nitrogen-doped titanium photocatalyst against human pathogens. Appl Environ Microbiol. 2006;72(9):6111-6116.

39. WU D, et al. Evaluation of the antibacterial efficacy of silver nanoparticles against Enterococcus faecalis biofilm. February 2014, Volume 40, Issue 2, Pages 285-290.

40. ZHANG FH, et al. The effect of a combined nanoparticulate/calcium hydroxide medication on the biofilm of Enterococcus faecalis in starvation phase. Shanghai Kou Qiang Yi Xue 2016;25(1):11-15. 